\title{
Dental cingulum (cingulate)
}

\author{
El cíngulo dental
}

\author{
Sandra Moreno, ${ }^{*}$ Freddy Moreno*
}

Dental cingulate represents a morphological characteristic scarcely studied in the dental field, but widely researched in biological and anthropological contexts. This morphologic structure, unknown or misunderstood by many dentists, represents the point of origin of different morphological dental traits. Traditionally, dental cingulate has been defined as the portion of enamel forming a convex protuberance in the cervical third of the palatal and lingual surfaces of anatomic crowns of upper and lower incisor and canine teeth. Thus, in the dental context, it has been considered as an exclusive morphological structure of incisor and canine teeth -as class- of human dentition. ${ }^{1}$

Nevertheless, within the bio-anthropological context, dental cingulate has been defined as an enamel bridge which connects the base of anterior teeth lobes at the cervical third with the cusps of posterior teeth in order to protect against possible injuries caused by fragments of hard foodstuffs during mammalian mastication processes. ${ }^{2}$ This original function, related to the gingival protection of primitive mammalians, was later complemented with the formation of the triphosphonic molar, which explains that dental cingulate was formed as a structural reinforcement (support) to dissipate forces generated from the cusps during occlusion. ${ }^{3}$ Therefore, from a macro-structural perspective, the dental cingulate represents a convex protuberance in the palatal and lingual surface of upper and lower incisors and canines, as well as a well-developed platform surrounding the cervical third of upper and lower molars. ${ }^{1,4}$

According to the tri-tubercular theory -which explains evolutionary development of mammal teeth-, posterior teeth count with an enamel collar called cingulum (upper molars) or cingulate (lower molars) which circumscribes the crown of all teeth at the height of the gingival third, resembling a stylar shelf. During odontogenesis from this stylar shelf different morphological dental traits emerge, such as cuspal talon and lobes which form the cingulum itself in anterior teeth, as well as tubercles or para-molar cusps (para-styles in upper and lower molars) which are present in vestibular, palatal or lingual surfaces of upper and lower molars respectively. This is the case of the proto-style-Carabelli cusp), para-style and protostylid. ${ }^{5-8}$

Even though in the anthropological context observation, recording and analysis of dental morphology through these morphological dental traits has become a valuable information source to assess biological relationships among past and present human populations, ${ }^{9}$ in the dental context, the cingulum (of anterior teeth) has been relegated to being described as an anatomical factor prone to bacterial plaque accumulation and increase of possibility to develop caries ${ }^{9-11}$ or to the generation of occlusal interferences in the shape of premature contacts. Both situations are frequently solved with selective enameloplasty and restorative treatment. ${ }^{12,13}$

Therefore, it is of the utmost importance to contrast the bio-anthropological concept of the cingulum when facing the controversial lack of knowledge of the evolutionary role of this morphological structure, reason which highlights the importance of it being considered:

1. Dental cingulate corresponds to a morphological structure which emerged during the evolution of the first mammals as a collar surrounding the crown of all teeth -anterior and posterior- at the level of the cervical third. Its main functions were protection of

\footnotetext{
* DDS, Biomedical Sciences Degree, Professor at the School of Dentistry of the Universidad del Valle (Cali, Colombia), Professor at the Universidad Pontificia Javeriana (Cali, Colombia).
}

(C) 2016 Universidad Nacional Autónoma de México, [Facultad de Odontología]. This is an open access article under the CC BY-NCND license (http://creativecommons.org/licenses/by-nc-nd/4.0/).

This article can be read in its full version in the following page: http://www.medigraphic.com/facultadodontologiaunam 
periodontal tissues from possible injury caused by hard foodstuffs as well as reinforcement of cervical enamel to enable absorption of forces coming from functional cusps during mastication.

2. In anterior teeth, the cingulate's evolutionary remnant is expressed in the lingual and palatal surfaces as a prominence constituted by as system of lobes and grooves, exhibiting wide morphological variability, whose function has been associated to directing food fragments during incision.

3. In anterior teeth, the cingulate is constituted in the origin platform of dental morphological traits such as the dental tubercle-which can be present in vestibular as well as palatal and lingual surfaces of respectively upper and lower incisors, as well as the interrupted groove.

4. In posterior teeth, the cingulum is formed in the morphogenetic origin platform of the so-called paramolar cusps-Carabelli's cusp, para-style and protostyle; whose cusp expression is the evolutionary remnant of this structure.

5. When the cingulum involutions in posterior teeth, the enamel of the crown's cervical third in proximity to the enamel-dentin junction becomes very thin, and is exposed to fractures elicited by tensile forces caused by mastication generating an associated type of lesion called abfraction.

\section{REFERENCES}

1. Berkovitz BKB, Holland GR, Moxham BJ. Oral anatomy, histology and embryology. 2nd edition. London: Mosby International; 2002.
2. Reynolds SH. The vertebrate skeleton. 2nd edition. Cambridge: Cambridge University Press; 1897.

3. Kermack DM, Kermack KA, Mussett F. The Welsh pantothere Kuehneotherium praecursoris. Zool J Linn Soc. 1968; 47: 407-423.

4. Hillson S. Teeth. Manuals in archaeology. 2nd edition. Cambridge: Cambridge University Press; 2005.

5. Osborn HF. The evolution of mammalian molars to and from the tritubercular type. The American Naturalist. 1888; 22 (264): 1067-1079.

6. Kraus BS. Morphologic relationships between enamel and dentine surfaces of lower first molar teeth. $J$ Dent Res. 1952; 31: 248-256.

7. Butler PM. Some functional aspects of molar evolution. Evolution. 1972; 26 (3): 474-483.

8. Duque JF, Ortíz M, Salazar L, Mejía C. Mamíferos: evolución y nomenclatura dental. Rev Estomat. 2009; 17 (2): 30-44.

9. Scott GC, Turner II CG. The anthropology of modern human teeth: dental morphology and its variation in recent human populations. London: Cambridge University Press; 1997.

10. Rodríguez JV. Dientes y diversidad humana: avances de la antropología dental. Bogotá: Universidad Nacional de Colombia; 2003.

11. Hernández J, Villavicencio J, Arce E, Moreno F. Talón cuspídeo: reporte de cinco casos. Rev Fac Odontol Univ Antioq. 2010; 21 (2): 208-217.

12. Nabeel S, Danish G, Hegde U, Mull P. Parastyle: clinical significance and management of two cases. Int J Oral Maxillofac Pathol. 2012; 3 (3): 61-64.

13. Rodríguez C, Moreno F. Paramolar tubercle in the left maxillary second premolar: a case report. Dental Anthropol. 2006; 19: 65-69.

\author{
Mailing address: \\ Freddy Moreno \\ E-mail: fmorenog @ javerianacali.edu.com
}

